\title{
Erratum to: Loss of Lean Body Mass as an Independent Risk Factor for Continuation of S-1 Adjuvant Chemotherapy for Gastric Cancer
}

Toru Aoyama, MD ${ }^{1,2}$, Taiichi Kawabe, $\mathrm{MD}^{1,2}$, Hirohito Fujikawa, $\mathrm{MD}^{1,2}$, Tsutomu Hayashi, MD $^{1,2}$, Takanobu Yamada, MD ${ }^{1,2}$, Kazuhito Tsuchida, MD $^{1,2}$, Norio Yukawa, MD $^{2}$, Takashi Oshima, MD, PhD ${ }^{2}$, Yasushi Rino, $\mathrm{MD}^{2}$, Munetaka Masuda, MD, $\mathrm{PhD}^{2}$, Takashi Ogata, MD, PhD', Haruhiko Cho, MD ${ }^{1}$, and Takaki Yoshikawa, MD, PhD ${ }^{1,2}$

${ }^{1}$ Department of Gastrointestinal Surgery, Kanagawa Cancer Center, Yokohama, Japan; ${ }^{2}$ Department of Surgery, Yokohama City University, Yokohama, Japan

\section{ERRATUM TO: ANN SURG ONCOL}

DOI 10.1245/S10434-014-4296-Z

In the original article there was an error in Fig. 3. Following is the corrected figure:

FIG. 3 Comparison of the treatment continuation rates between patients who experienced a lean body-mass loss of $<5 \%$ and those who lost more than $5 \%$ of their lean body mass

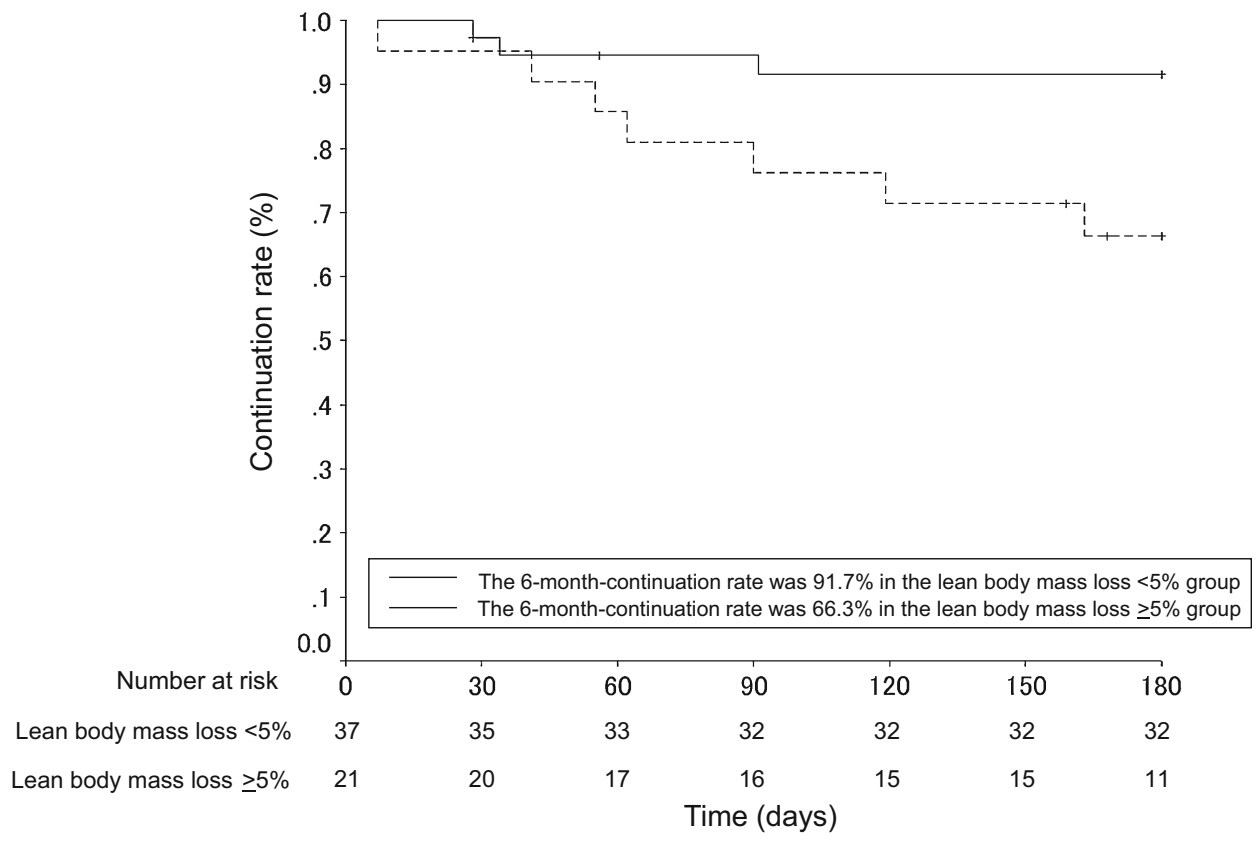

The online version of the original article can be found under doi:10.1245/s10434-014-4296-z.

(C) Society of Surgical Oncology 2015

Published Online: 14 July 2015

T. Yoshikawa, MD, PhD

e-mail: yoshikawat@kcch.jp 